\title{
TECHNICAL EFFICIENCY IN MALAYSIAN MANUFACTURING FIRMS: A STOCHASTIC FRONTIER ANALYSIS APPROACH
}

\author{
MOHD FAHMY-ABDULLAH ${ }^{1}$, LAI WEI SIENG ${ }^{2 *}$ AND HAMDAN MUHAMAD ISA $^{3}$ \\ ${ }^{1}$ Faculty of Technology Management \& Business, Universiti Tun Hussein Onn Malaysia, 86400 Parit Raja, Batu Pahat, \\ Johor, Malaysia. ${ }^{2}$ Centre of Sustainable and Inclusive Development, Faculty of Economics and Management, Universiti \\ Kebangsaan Malaysia. ${ }^{3}$ Department of Statistics Malaysia, Putrajaya, Malaysia.
}

*Corresponding author:laiws@ukm.edu.my

Submitted final draft: 19 October $2020 \quad$ Accepted: 22 November $2020 \quad$ http://doi.org/10.46754/jssm.2021.08.021

\begin{abstract}
Liberalisation challenges, such as those that arise with the establishment of the ASEAN Free Trade Area (AFTA) and elimination of trade barriers, have led to competition among local and foreign manufacturers, requiring Malaysian manufacturing companies to achieve high productivity to address the emergence of new operations by increasing their industrial efficiency and performance. This article aims to measure the level of technical efficiency and analyse the factors that contribute to technical inefficiency in the Malaysian manufacturing industry in 2015. This study uses data from 8,653 firms based on the latest census (2015) obtained from the Statistics Department using the Stochastic Frontier Analysis (SFA). Based on the results, the companies' overall technical efficiency level was high at 0.812 . For the determinants of technical efficiency, it was found that ratio of medium to high level of education, company size, information and communication technology spending, training expenses and wage rates showed a positive relationship with technical inefficiencies. The manufacturing industry needs to focus on investing in human capital and scale economic achievement, and high technology production that will increase the technical efficiency level of companies and employees.
\end{abstract}

Keywords: Technical efficiency, Technical inefficiency, Manufacturing industry, Stochastic Frontier Analysis.

\section{Introduction}

The manufacturing sector is the largest contributor to Malaysia's total export and is the second largest contributor to its gross domestic product (GDP). The manufacturing industry recorded a gross output value of RM1,142 billion in 2015, with a compounded annual growth rate (CARG) of 6.4 per cent per annum (Economic Census, 2016). In fact, GDP growth was 22.8 per cent in 2015 while positive growth performance was recorded at 4.9 per cent, and total investment from 2011 to 2014 was RM159.1 billion. By 2020, the manufacturing industry has been expected to contribute 22.1 per cent of the country's GDP and is targeted to grow at an average annual rate of 5.1 per cent (Malaysia Productivity Corporation Report 2015/2016).

The establishment of the ASEAN Free Trade Area (AFTA) entails the elimination of trade barriers, which has caused industries to experience volatility (MITI, 2014). Based on Malaysia's 2015 GDP report, the manufacturing sector has experienced a decline of 0.1 per cent (22.8 per cent) compared with 2014 (22.9 per cent). Manufacturing growth also declined by 4.9 per cent in 2015 as compared to 6.2 per cent in 2014. The decline has been attributed to a contraction in palm oil manufacturing (National Accounts Gross Domestic Product, 2016). Trade liberalisation may widen the market and open business opportunities to the local industry as subcontractors to multinational corporations (MITI, 2013). However, this will also push the manufacturing industry's ability to produce optimum output using the existing input (Malaysia Productivity Corporation Report 2014/2015).

Strategies designed and implemented to transform the manufacturing industry in the 11th Malaysia Plan from 2016 to 2020 encompasses five key areas focusing on producing complex 
and diverse products; increasing productivity through automation; promoting an innovationdriven growth; and, strengthening and accelerating growth. Internationalisation adds further pressure on the industry and this situation requires the technical efficiency (TE) level to be high enough to address the emergence of new operations. TE and new technologies that are ultimately capable of boosting the country's economic growth momentum are included in the National Key Result Areas (NKRA) to ensure that the manufacturing industry becomes the driver of national transformation. An industry that is not prepared to raise the level of TE certainly cannot boost the country's economic growth momentum as a result of economic openness and trade liberalisation (Adhikary, 2011).

This study aims to evaluate the technical efficiency and inefficiency factors in the Malaysian manufacturing industry using the latest data collected by the Department of Statistics Malaysia (DOSM) through its 2015 Economic Census. The company-level data used in this study is the latest to be released by DOSM, and permission was needed to obtain them through a long process. This study is in line with the country's target of developing the manufacturing industry into a competitive player globally. The first analysis determines the level of technical efficiency, and the second identifies the factors of inefficiency among the companies studied. The second section of this article is a review of previous studies. The third section discusses the research methodology, data sources and model specification. The fourth section reports the results, and the last provides conclusions and policy implications.

\section{Literature Review}

The TE study is conducted in various fields or organisations depending on the objective and selection of inputs and outputs. Farell (1957) was the first to study the measurement of efficiency and inefficiency properties in production. He pointed out that inefficiency occurs when maximum output cannot be achieved from the use of inputs selected for processing purposes. Njikam (2003) compared trade reforms from 1989 to 1992, and 1995 to 1998 in Cameroon, and found that positive growth in companies has occurred as average TE levels increased at a rate of 1.39 per cent per annum after a trade, compared to 0.76 per cent in the previous quarter. In addition, studies using the DEA Two-Stage method were conducted by Noor and Ismail (2007) on the data of manufacturing companies gathered through a survey in 1997. The results show that most of the companies' operations are relatively inefficient. The study concludes that all of these inefficient companies were operating on an increasing return of scale basis. The size of the company and the level of engineering had shown a positive and significant impact on the TE value. Meanwhile, Wadud (2008) studied the relationship between TE and productivity growth of the manufacturing industry in Malaysia using the Malmquist productivity index, and found that the majority of industries operated with a low TE level with little or no improvement over time. Therefore, the average annual growth in productivity is low due to a decrease or technical slowdown. A study using the Two-Level DEA method was conducted by Noor and Ismail (2007) on manufacturing companies using 1997 survey data. The results also showed that most are relatively inefficient. The study concluded that all these inefficient firms operated in the share returns in line with the skeleton. The company size and mechanisation level have also been shown to bring positive and significant impact on TE value.

Radam et al. (2008) examined the TE of small- and medium-sized industries (SMI) in Malaysia and found that the value-added operations of SMIs were lower compared with large industries. Based on the Stochastic Frontier Analysis (SFA) result, they also found that only three per cent of the companies' operations studied may be considered as efficient, with the TE values ranging from 0.30 and 97.1 per cent. The conclusions of this study indicated that SMIs were relatively more efficient than large industries, with higher technical inefficiency values. 
Ismail and Jajri (2008) noted that the most transport equipment sub-industries have a higher technical efficiency change (TEC) than technological change (TC) in total factor productivity (TFP) growth. In fact, the findings also showed that when appropriate technology is used, TE will increase, thus increasing TFP growth. Ismail and Tendot (2008) found that the level of TE in Malay manufacturing companies was still low and less competitive. The findings also found that the average TE level, company size and education level were significant in determining the level of company TEs. .

In addition, Fahmy-Abdullah et al. (2017) found that the average TE level in the Malaysian manufacturing industry was moderate. The results also showed that inefficiencies in determining the wage rate of workers, and information and communication technology expenditure may affect a company's technical competence. Studies by Mahadevan (2002a), Mahadevan (2002b) and Mahadevan (2002c) also leverage the same data through different approaches in TFP growth studies. The difference in the methodology used has led to the same conclusion that TFP in the manufacturing industry is still at a low level. In addition, there are many recent world studies that measured the level of efficiency and TFP growth in the manufacturing industry, including Mitra et al. (2013), Arnold et al. (2015) and Harris and Moffat (2015).

Capital-labour ratio is another factor that is known to increase TE (Minh et al., 2007). Through the capital-labour ratio, the amount of capital allocated for each employee in the production process can be identified. When a firm can capitalise on high capital volumes, the positive impact on efficiency and productivity may be achieved in line with the maximum machine utilisation in the production process (Bertrand, 2013). However, in the event of a capital increase such as technological purchases and, at the same time, if the employees' skill is not upgraded, it will affect the company's efficiency level as the employees will face challenges in adapting to the new technologies acquired (Noor
Aini et al., 2008). Besides that, skilled labour may improve and encourage the production of quality goods and services. A skilled workforce may create or innovate on the use of technology to enhance the company's TE level (Essmui et al., 2013). Olatunji and Ibidunni (2013) and Ismail \& Zainal Abidin (2015) showed that training expenses is one of the factors that may reduce technical inefficiency. When training implemented is not in line with the needs of employees, there will be wastage and losses incurred (Fahmy-Abdullah et al., 2018). Employee's skills are also associated with their education level. Education is one of the key roles in identifying company performance, including output, profitability and productivity (Malaysia Productivity Corporation Report 2016/2017).

Company size also plays an important role in increasing company efficiency (Khalifah, 2013). In the manufacturing sector, SMIs are defined as companies with sales of not less than RM300,000 and not exceeding RM50 million, while large companies may earn more than RM50 million (SME CORP, 2013). An improved TE level is positively related to the increase in company size (Batra \& Tan, 2003; Charoenrat \& Harvie, 2013), and companies that use more sophisticated machinery have higher levels of efficiency (Fahmy-Abdullah et al., 2019). In fact, the implementation of the Productivity-Based Wages System (SUBP) may bring benefits as this system contributes to the company's competitiveness (National Productivity Corporation, 2010). In addition, investments in information and communication technology (ICT) may result in a positive impact on efficiency (Ismail \& Zainal Abidin, 2015). Investments on data, physical input, incentives, or subsidies and capital stocks to promote innovation and development of strategic ICT plans may enhance the company's TE level (Liew et al., 2012).

Furthermore, Murthy et al. (2009) emphasised the benefits of employees with higher education are greater in developing countries than in developed countries. The study by Ismail and Tendot (2008) highlighted 
the importance of employee education level as an important factor in influencing company competence in Malaysia. Most of the previous research on the manufacturing industry in Malaysia has not used data at the firm level to measure TE level.

However, studies, such as Sulaiman (2012), Mustapha et al. (2013) and Ismail and Abidin (2017), have used data at the industry level. In addition, research on the determinants of technical inefficiencies has also been overlooked to measure efficiency as stated by Mahadevan (2002a), Mahadevan (2002b), Mahadevan (2002c) and Said et al. (2004). TE levels may be measured accurately when using companylevel data, taking into account the factors of inefficiency that will drive improvement efforts. Tingley et al. (2005) stated that estimation using company data as an individual is preferable because further analysis of factors affecting the level of efficiency may be studied. In fact, research on the determinants of technical inefficiencies has also been overlooked to derive value and efficiency. Battese and Coelli (1995) asserted that in taking technical inefficiency into account, company-level data may play an important role in reflecting accurate TE values.

In conclusion, company-level data, with the technical inefficiency factors being considered, may provide new findings and TE values that are more significant and accurate. Therefore, this study determines the extent of efficiency and inefficiency factors in the manufacturing industry in Malaysia.

\section{Methodology, model specification and data}

The Data Envelopment Analysis (DEA) and SFA models were commonly used to estimate the maximum output level. The DEA model was a non-parametric approach that could not make any assumptions regarding production functions. It could not identify the differences between inefficiencies and random errors (Coelli et al., 2005). However, DEA was the best-performing manufacturing practice model based on input and output observations. SFA model had been proposed by Battese and Coelli
(1995) to calculate a company's TE value. The SFA model's main advantage was that it produced better results because the statistical method used tended to assume the stochastic features of the data obtained (Tingley et al., 2005). In addition, this method was easily adapted to the environmental variables (Coelli et al., 2005). The SFA approach also identified inconsistent data in the analysis. Cullinane et al. (2006) stressed that the SFA model could analyse structure, and examine the determinants and performance of the manufacturer. Tingley et al. (2005) compared DEA and SFA models to demonstrate that the measurement of TE level using SFA was better and more consistent than DEA because of the low variance. In fact, the SFA model was not only capable of measuring technical inefficiencies, but it could also identify random shocks that were beyond the manufacturers' control, which could impact their production (Jarboui et al., 2015).

The original SFA specification involved production models devoted to cross-sectional data, which had conditions for errors consisting of two components. The first described the random effects $\left(v_{\mathrm{i}}\right)$ and the second explained the incomplete techniques $\left(u_{\mathrm{i}}\right)$. This original specification could be obtained from a comprehensive study by Greene (2008). Battese and Coelli (1995) proposed an easy model that could be used to measure inefficiencies. Following that, the SFA model that contained the company's assumed effects scattered as a normal trimmed random variable was proposed in the same study. The model species may be written as in Equation 1;

$$
\mathrm{Y}_{i}=\mathrm{X}_{i} \beta+\left(v_{i}-u_{i}\right)
$$

where $\mathrm{Y}_{i}$ is the logarithm for production for firm $\mathrm{i}$-th $(\mathrm{i}=1,2, \ldots, \mathrm{N}) . \mathrm{Xi}$ is a vector $(\mathrm{k} x$ 1) transformation of the input for firm $I ; b$ is a vector $(\mathrm{k} \times 1)$ unknown parameter; $u_{i}$ is a non-negative random variable, represents the technical inefficiency, and is assumed to be independently distributed as truncations at zero of the $N\left(\mu, \sigma_{u}^{2}\right)$ distribution; $v_{i}$ is a random error assumed to be iid $N\left(0, \sigma_{v}^{2}\right)$. 
The coefficient of the frontier and inefficiency effect model in Equation 1 could be measured using the maximum likelihood method (MLE). The parameter of Battese and Broca (1997) was employed by replacing $\mathrm{s}_{\mathrm{v}}{ }^{2}$ and $\mathrm{s}_{\mathrm{u}}{ }^{2}$ with $\mathrm{s}^{2}=\mathrm{s}_{\mathrm{v}}{ }^{2}+\mathrm{s}_{\mathrm{u}}{ }^{2}: \mathrm{g}=\mathrm{s}_{\mathrm{u}}{ }^{2} /\left(\mathrm{s}_{\mathrm{v}}{ }^{2}+\mathrm{s}_{\mathrm{u}}{ }^{2}\right.$ ) (see Coelli dan Battese, 1996), where $\mathrm{g}$ had the value between 0 and 1 . If $H_{0}: \mathrm{g}=0$ is rejected, this proved that the actual data deviations from the boundary functions were due to technical inefficiency. This means the null hypothesis about no technical inefficiency was rejected. To test the null hypothesis, a generalised likelihoodratio (LR) L test was performed with the test statistic as follows in Equation 2;

$$
1=-2\left\{\ln \left[L\left(H_{0}\right)\right]-\ln \left[L\left(H_{1}\right)\right]\right\}
$$

with $L\left(H_{0}\right)$ and $L\left(H_{1}\right)$ shows the probability function under null hypothesis and alternative hypothesis. Based on LR Test, hypothesis $\left(H_{0}\right.$ : $=0)$ could be rejected. Thus the basic model without time factor would be applied according to model of Battesse et al. (1988). TE of production for $\mathrm{i}$-th firm was defined as ratio of real output to potential output in Equation 3:

$$
\mathrm{TE}_{i}=E\left[\exp \left(-u_{i}\right)\right]
$$

Since $u_{i}$ is a non-negative variable, the efficiency is located between zero and one. A firm is technically competent if the TE value was 1 (i.e. ineffective effect is 0 ). The study used two approaches — the Cobb-Douglas and Transcendental Logarithmic (Translog) functions (Coelli et al., 2005). Hypothesis test was carried out to determine the appropriate model by selecting the best MLE level. The SFA model based on the Cobb-Douglas function could be written as in Equation 4.

$$
\ln \mathrm{Y}_{\mathrm{i}}=\beta_{0}+\sum_{j=1}^{n} \beta_{j} \ln X_{i j}+\left(v_{i}-u_{i}\right)
$$

While the SFA model based on the Translog function could be written as Equation 5.

$$
\ln Y_{\mathrm{i}}=\beta_{0}+\sum_{j=1}^{n} \beta_{j} \ln X_{i j}+\frac{1}{2} \sum_{j}^{n} \sum_{l}^{n} \beta_{j l} \ln X_{i j} \ln X_{i j}+\left(v_{i}-u_{i}\right)
$$

where $Y_{i}$ is the $\log$ of the observed output of the $i$-th establishment. $X$ variables are the $\log$ of inputs, while subscripted $j$ and $i$ indicate the inputs. In Equation (4) and (5), $\mathrm{Y}_{i}$ is the output, and the three inputs are the values of the capital $\left(\mathrm{K}_{i}\right)$, labour $\left(\mathrm{L}_{i}\right)$ and intermediate input $\left(\mathrm{II}_{i}\right)$.

The first objective of this study was to measure the level of technical efficiency of the manufacturing industry in Malaysia. The FRONTIER 4.1 programme developed by Battese and Coelli (1995) was used to analyse the data. The second objective was to determine the determinants of the inefficiency of the manufacturing industry. The variables involved in the technical inefficiency of the SFA model were stated in Equation 7.

$$
\begin{aligned}
u_{i}= & \delta_{0}+\delta_{1} \operatorname{lnRCL}_{i}+\delta_{2} \operatorname{lnRSEC}_{i}+\delta_{3} \operatorname{lnRTER}_{i}+ \\
& \delta_{4} \mathrm{DSME}_{i}+\delta_{5} \operatorname{lnCE}_{i}+\delta_{6} \operatorname{lnTRAIN}_{i} \\
& +\delta_{7} \operatorname{lnSAL} \ln _{i}+\delta_{8} \operatorname{lnR} \& \mathrm{D}_{i}
\end{aligned}
$$

where $u_{i}$ represents technical inefficiency. $\mathrm{RCL}_{i}$ represents the ratio of the total capital divided by the number of employees in the $i$-th firm. RSEC $_{i}$ represents the ratio of workers with a diploma and STPM education level or equivalent for the $i$-th firm. RTER represents the ratio of workers with higher education levels, which included postgraduate degrees or equivalent for the $i$-th firm. DSME is a dummy for the $i$-th firm, with small firms representing 1, while the others represent $0 . \mathrm{CE}_{i}$ represents the communication expenses for firm $i$-th. TRAIN ${ }_{i}$ represents the total expenditure for employee training for $i$-th firm. SAL $\mathrm{S}_{i}$ represents the wage rate for the $i$-th firm. $\mathrm{R} \& \mathrm{D}_{i}$ is the research and development spending for firm $i$-th.

Company-level data in this study were obtained by DOSM in a survey in 2015', involving 332 sub-industries at three-digit level according to Malaysian Standard Industrial Classification (MSIC) 2008. Some of the original data had to be excluded due to lack

1 The firm level data used in this study is the latest that has been released by the Department of Statistics Malaysia (DOSM) based on Economic Census 2015. The data obtained needed permission and involved a long process. 
of information, such as incomplete output or unquoted capital, and the number of employees was small and did not meet the purpose of SMIs that affected the sample analysis. In total, 8,653 firms were involved in this study. As a common practice in SFA studies, these variables had been mean-corrected prior to estimation. Besides that, all monetary variables were expressed in 2010 Malaysian Ringgit value.

\section{Results}

The FRONTIER 4.1 programme developed by Battese and Coelli (1995) was used to determine whether to use the Cobb-Douglas or Translog production function. In addition, the programme could also analyse the technical competence level and factors determining the inefficiency of the manufacturing industry in Malaysia as follows;

$H_{0}=$ Cobb-Douglas production function

$H_{1}=$ Translog production function

Test statistic LR used to test the null hypotheses $\left(\mathrm{H}_{0}: \beta_{\mathrm{ij}}=0\right)$. This value was compared with critical value at $1 \%$ significance level: 2562.118. The results (Table 1) show that the Cobb-Douglas production function was rejected at $1 \%$ significance level, while the Translog production function was more appropriate to represent the data analysis.

According to Baten et al. (2009), the Translog production function was better than Cobb-Douglas because it could demonstrate the real curve function rather than just assumptions.
Based on these results, it was shown that the Translog production function is better than Cobb-Douglas as it could show actual curve functions rather than mere assumptions (Baten et al., 2009). In fact, the Translog production function was relatively flexible because it did not require assumptions about the constant output elasticity (this represented output variability from the input variability level) or the alternation between inputs (this represented the degree to which inputs were capable of replacing others as a result of relative change in prices and, at the same time, maintain constant output; values ranged from 0 (which indicated that the input was fixed with unchanged proportions) to infinity (in this case, the input was a perfect substitute and its use was very sensitive on relative price changes) (Jarboui et al., 2013).

The hypothesis testing would determine that there was no technical inefficiency $\left(\mathrm{H}_{0}: \gamma\right.$ $=0$ ) in the manufacturing industry in Malaysia as shown in Table 2. If $\mathrm{H}_{0}$ : $=0$ was rejected, this proved that deviations of actual data from the boundary function would be due to technical inefficiency. This meant that the null hypothesis of no technical inefficiency could be rejected as follows;

$$
\begin{aligned}
& H_{0}=\text { No Effect of technical Inefficiency } \\
& H_{1}=\text { Effect of technical Inefficiency exists }
\end{aligned}
$$

The calculated LR statistic value to test the null hypothesis, $\mathrm{H}_{0}$ : $=0$ is 1665.32 . The LR test shows that the statistical value obtained is greater than the critical value (19.38) at the $1 \%$ significance level (Kodde dan Palm, 1986).

Table 1: Result of Cobb-Douglas and translog hypothesis testing

\begin{tabular}{lc}
\hline \multicolumn{1}{c}{ Null Hypotheses } & Cobb-Douglas \\
& $\left(\boldsymbol{H}_{\boldsymbol{0}}: \mathbf{)}\right.$ \\
\hline LR Statistic & $2562.12 * * *$ \\
Critical Value & $11.34 * * *$ \\
Result & $\mathrm{H}_{\mathrm{o}}$ rejected \\
\hline
\end{tabular}

Note: *** significant at $1 \%$ level, obtained from Chi-Square distribution table 
Table 2: Results of hypotheses testing

\begin{tabular}{cc}
\hline Null hypotheses & Cobb-Douglas \\
& $\left(\boldsymbol{H}_{\boldsymbol{0}}:\right)$ \\
\hline LR Statistic & $19.38^{* * *}$ \\
Critical Value & $1665.32^{* * *}$ \\
Result & $\mathrm{H}_{0}$ rejected \\
\hline
\end{tabular}

Note: $* * *$ and $* * *$ significant at $1 \%$ level, obtained from Kodde and Palm (1986)

This demonstrated the effects of technical inefficiency in the manufacturing industry. This test was crucial to confirm the certainty of the firmtech's inefficiency, which enabled further testing to identify the factors of inefficiency using the data obtained. Battese and Coelli (1995) asserted that with taking technical inefficiency factors into account, the TE decision would be more accurate and significant.

Table 3 shows the estimates of parameter using the Translog production function approach selected based on hypothesis testing. The results

Table 3: Results of SFA parameter estimation

\begin{tabular}{|c|c|c|}
\hline Variable & Parameter & Coefficient of MLE \\
\hline Constant & $\beta_{0}$ & $\begin{array}{l}2.591 * * * \\
(63.395)\end{array}$ \\
\hline Ln Capital & $\beta_{1}$ & $\begin{array}{c}0.052 * * * \\
(5.059)\end{array}$ \\
\hline Ln Labour & $\beta_{2}$ & $\begin{array}{l}0.528 * * * \\
(37.056)\end{array}$ \\
\hline Ln Intermediate Input & $\beta_{3}$ & $\begin{array}{c}0.3701 * * * \\
(37.868)\end{array}$ \\
\hline$(\text { Ln Capital })^{2}$ & $\beta_{4}$ & $\begin{array}{l}0.029 * * * \\
(14.424)\end{array}$ \\
\hline$(\text { Ln Labour })^{2}$ & $\beta_{5}$ & $\begin{array}{l}0.093 * * * \\
(18.838)\end{array}$ \\
\hline$(\text { Ln Intermediate Input })^{2}$ & $\beta_{6}$ & $\begin{array}{l}0.097 * * * \\
(43.675)\end{array}$ \\
\hline $\begin{array}{l}\left(\text { Ln Capital) }{ }^{*}\right. \\
(\text { Ln Labour })\end{array}$ & $\beta_{7}$ & $\begin{array}{c}-0.009 * * * \\
(-3.937)\end{array}$ \\
\hline $\begin{array}{l}\text { (Ln Capital) } \\
\text { (Ln Intermediate Input) }\end{array}$ & $\beta_{8}$ & $\begin{array}{l}-0.023 * * * \\
(-13.180)\end{array}$ \\
\hline $\begin{array}{l}\text { (Ln Labour) } \\
\text { (Ln Intermediate Input) }\end{array}$ & $\beta_{9}$ & $\begin{array}{r}-0.073 * * * \\
(-27.260)\end{array}$ \\
\hline Sigma-squared & $\sigma^{2}=\sigma_{v}^{2}+\sigma_{u}^{2}$ & $\begin{array}{l}0.033 * * * \\
(56.246)\end{array}$ \\
\hline Gamma & $\gamma$ & $\begin{array}{c}0.061 * * * \\
(8.354)\end{array}$ \\
\hline Log-Likelihood Function & & $2483.922^{* * *}$ \\
\hline
\end{tabular}

Note: $* * *$ indicates significant level of $1 \% t$ values in parentheses 
showed that all variables in the manufacturing industry were significant at the $1 \%$ significance level. Overall, gamma parameter $(\gamma)$ obtained showed positive and significant values. This proved that technical inefficiency had significant impact on the manufacturing industry production in Malaysia. Furthermore, the squared sigma value $\left(\mathrm{s}^{2}=\mathrm{s}_{\mathrm{v}}{ }^{2}+\mathrm{s}_{\mathrm{u}}{ }^{2}\right)$ also indicated significantly that a company was not operating efficiently. Overall, the efficiency level of manufacturing industry in Malaysia was at a high level in 2015.

Results of FRONTIER 4.1 analysis showed that the average TE level for 8,653 companies in this study was 0.812 as shown in Table 4 . This means that almost all firms operated at a high level to produce output or optimum production.

Table 5 shows the results of the technical inefficiency variables. The negative sign obtained from the analysis showed that when there was an increase in the variables, there would be a reduction in the technical inefficiency. On the other hand, if a positive sign was obtained, it indicated an increase in the technical inefficiency of the company.

Based on the analysis, the proportion of workers with middle and high level of education could reduce technical inefficiency at $1 \%$ significance level. This suggested that the number of middle-aged, 12 per cent and highly qualified graduates representing 7.5 per cent for the entire workforce in 2015 (Economic Census, 2016) had greatly contributed to improvements in the manufacturing industry efficiency in Malaysia. Idiong (2007) showed that education was a very important factor in the technology level to improve the company's efficiency and productivity. In fact, improving the quality of education among employees could increase the production rate, the level of technology and influence the company's efficiency and productivity (Ajibefun 2008; Murthy et al, 2009).

The company size, meanwhile, showed a negatively significant relationship at $1 \%$ significance level; which means the technical inefficiency of companies could be reduced. When there was an increase in company size by one percent, technical inefficiency could be reduced by 0.08 per cent. Based on a survey, 82.5 per cent of the companies involved were small- and medium-sized enterprises, compared with only 17.5 per cent of big companies. The technical efficiency would increase with

Table 4: Technical efficiency of the manufacturing industry in Malaysia

\begin{tabular}{cccc}
\hline & Min & Median & Maximum \\
\hline Y ('000) & 67 & 8,625 & $21,932,012$ \\
K ('000) & 2 & 1,931 & $6,830,609$ \\
L (total) & 2 & 51 & 15,676 \\
II ('000) & 9 & 5,860 & $20,276,105$ \\
RCL ('000) & 1.015 & 35.811 & $21,517.474$ \\
SEC ('000) & 0.000 & 0.088 & 1.000 \\
RTER ('000) & 0.000 & 0.028 & 1.000 \\
DSME (dummy) & 0 & 1.000 & 1 \\
CE ('000) & 2 & 17 & 750,087 \\
TRAIN ('000) & 0 & 0.440 & 15,000 \\
SAL ('000) & 1.232 & 18.928 & $1,528.899$ \\
R\&D ('000) & 0 & 0 & $1,703,613$ \\
No. of firms & & & \\
Average Technical & & & \\
Efficiency & & & \\
\hline
\end{tabular}


Table 5: Determinants of technical inefficiency variables

\begin{tabular}{lcc}
\hline \multicolumn{1}{c}{ Variable } & Parameter & Coefficient of MLE \\
\hline Constant & $\delta_{0}$ & 0.8104 \\
& & $(22.842)^{* * *}$ \\
Ln Ratio Capital-Labour & $\delta_{1}$ & -0.005 \\
Ln Ratio SEC & $\delta_{2}$ & $(-0.948)$ \\
& & -0.006 \\
Ln Ratio TER & $\delta_{3}$ & $(-3.003)^{* * *}$ \\
& & -0.154 \\
Dummy Size Firm & $\delta_{4}$ & $(-4.193)^{* * *}$ \\
& & -0.076 \\
Ln ICT Expenses & $\delta_{5}$ & $(-4.114)^{* * *}$ \\
& & -0.173 \\
Ln Training Expenses & $\delta_{6}$ & $(-28.468)^{* * *}$ \\
Ln Wage Rate & $\delta_{7}$ & -0.011 \\
& & $(-5.105)^{* * *}$ \\
Ln Research and Development & $\delta_{8}$ & -0.005 \\
& & $(-3.442)^{* * *}$ \\
\end{tabular}

Note: $* * *$ indicates significant level of $1 \% t$ values in parentheses

company size (Batra and Tan, 2003) and some other studies also showed that company size could influence TE value (Amornkitvikai et al., 2014).

Next, ICT expenditure was found to have a positive and significant relationship with increasing technical inefficiency. When there was an increase in the ICT expenditure by one per cent, the technical inefficiency would decrease by 0.17 per cent. Improvements in capital stock and physical input could be made from ICT investments to enhance competence (Mahadevan and Mansor, 2007, Fahmy-Abdullah et al., 2018). Similarly, the determinant of training expenses could reduce the inefficiency of the manufacturing firms in Malaysia. When there is a one per cent increase in training expenses, technical ineffectiveness could be reduced by 0.01 per cent. Investments in human capital such as employee training could provide a positive return over the period of employees' service, and could provide skilled manpower as well as reducing dependency on skilled workers, thus helping to create a high- income skilled workforce (Fahmy-Abdullah et al., 2017).

In addition, wage rates played an important role with real coefficients of -0.005 and $5 \%$ significance level. This showed that when employees' wages increased by one per cent, the technical inefficiency would decrease by 0.005 points. Based on the Economic Census (2016), the average monthly manufacturing salary had risen from RM2,046 a month in 2010, to RM2,614 a month in 2015. This had also led to a decrease in technical inefficiency. Paying the appropriate rate of pay could increase the employees' self-motivation in carrying out a task which was an important motivator and stimulant for employees to increase production in the future (Ismail et al., 2009). Meanwhile, the results found that the determinants of capitalratio had no significant relationship to reduce the technical inefficiency. Based on the Economic Census (2016), manufacturing companies spent almost RM190 million on salaries for 1.4 million workers. However, this could not reduce technical inefficiency because most of 
the companies were focusing on capital gains. Also, research and development expenditure saw no significant relationship with inefficiency level. Based on a survey, 82.5 per cent of the companies involved were small- and mediumsized entities, which most did not emphasise research and development that could increase their TE.

\section{Conclusion}

The study aims to examine the efficiency level and analyse the factors determining technical inefficiency of manufacturing industry in Malaysia. This study involved 8,653 firms where data obtained from DOSM in 2015. Translog production function was applied to determine the level of efficiency and determinants of firm inefficiency. Overall, the level efficiency for manufacturing industry in Malaysia was high, with an efficiency of 0.81 . Subsequent results indicated that technical inefficiency factors included the ratio of employees with middleto high-level of education, company size, ICT spending, training expenses and wage rates.

In terms of policy implications, the findings in this study highlighted the need for the manufacturing industry to improve its efficiency level, particularly emphasising the determinants that could increase production. First, to produce a skilled workforce, sufficient level of education must be provided. Emphasis should be placed on improving skills and capabilities in leadership, engineering, quality and cost management. This could help the industry to reduce dependency on low-skilled employees, thus creating a knowledgeable workforce. Second, the transfer of technology and changes in the role of policymakers were needed to enhance innovation, competitiveness and growth. Hence, the increase in ICT spending should continue as it could help companies to increase its business prospects, as well as efficiency and productivity. Third, employee training was a long-term asset that could enhance skills and capabilities, besides producing competitive employees. Lastly, to motivate and improve efficiency and productivity that could increase the amount of output, the firm should increase wage rates among workers.

\section{Acknowledgements}

We are deeply indebted to DOSM for providing us the data of this research. The authors wish to acknowledge the Higher Education Ministry, Universiti Tun Hussein Onn Malaysia (UTHM) and Universiti Kebangsaan Malaysia (UKM) for providing the funds, facilities and assistance to carry out this study.

\section{References}

Ajibefun, I. A. (2008). Technical efficiency analysis of micro- enterprises: Theoretical and methodological approach of the stochastic frontier production functions applied to Nigerian data. Journal of African Economies, 17, 161-206.

Amornkitvikai, Y., Harvie, C., \& Charoenrat, T. (2014). Estimating a technical inefficiency effects model for Thai Manufacturing and Exporting Enterprises (SMEs): A Stochastic Frontier (SFA) and Data Envelopment Analysis (DEA) Approach. In Proceedings of Informing Science \& IT Education Conference (InSITE) (pp. 363-390).

Arnold, J. M., Javorcik, B., Lipscomb, M., \& Mattoo, A. (2015). Services reform and manufacturing performance: Evidence from India. The Economic Journal.

Baten, M. A., Kamil, A. A., \& Haque, M. A. (2009). Modeling technical inefficiencies effects in a stochastic frontier production function for panel data. African Journal of Agricultural Research, 4(12), 1374-1382.

Batra, G., \& Tan, H. (2003). SME technical efficiency and its correlates: Cross-national evidence and policy implications. World Bank, Washington, DC.

Battese, G. E., \& Broca, S. S. (1997). Functional forms of stochastic frontier production functions and models for technical inefficiency effects: A comparative study 
for wheat farmers in Pakistan. Journal of Productivity Analysis, 8(4), 395-414.

Battese, G. E., \& Coelli, T. J. (1995). A model for technical inefficiency effects in a stochastic frontier production function for panel data. Empirical Economics, 20(2), 325-332.

Battese, G. E., \& Coelli, T. J. (1988). Prediction of firm-level technical efficiencies with a generalized frontier production function and panel data. Journal of Econometrics, 38(3), 387-399.

Charoenrat, T., Harvie, C., \& Amornkitvikai, Y. (2013). Thai manufacturing small and medium sized enterprise technical efficiency: Evidence from firm-level industrial census data. Journal of Asian Economics, 27, 42-56.

Coelli, T. J., Rao, D. S. P., O’Donnell, C. J., $\&$ Battese, G. E. (2005). An introduction to efficiency and productivity analysis. Springer Science \& Business Media.

Cullinane, K., Wang, T. F., Song, D. W., \& Ji, P. (2006). The technical efficiency of container ports: comparing data envelopment analysis and stochastic frontier analysis. Transportation Research Part A: Policy and Practice, 40(4), 354-374.

Economic Census 2016. (2017). Putrajaya: Jabatan Perangkaan Malaysia.

Essmui, H., Madeline, B., Faridah, S., \& Shamshubarida, R. (2013). Technical efficiency of manufacturing enterprises in Libya: A stochastic frontier analysis. International Journal of Management \& Information Technology, 5(2), 528-535.

Fahmy-Abdullah, M., Ismail, R., Sulaiman, N., \& Talib, B. A. (2017). Technical efficiency in transport manufacturing firms: Evidence from Malaysia. Asian Academy of Management Journal, 22(1), 57-77.

Fahmy-Abdullah, M., Sieng, L. W., \& Isa, H. M. (2018). Technical efficiency in Malaysian textile manufacturing industry: A Stochastic Frontier Analysis (SFA) approach.
International Journal of Economics and Management, 12(2), 407-419.

Fahmy-Abdullah, M., Sieng, L. W., \& Ridzuan, S. (2019). Data envelopment analysis (DEA) two stages in identify determinants factor of efficienct techniques for transport in manufacturing firms. Sains Malaysiana, 48(4), 901-908.

Farrell, M. J. (1957). The measurement of productive efficiency. Journal of the Royal Statistical Society. Series A (General), 120(3), 253-290.

Greene, W. H. (2008). The econometric approach to efficiency analysis. The Measurement of Productive Efficiency and Productivity Growth, 92-250.

Harris, R., \& Moffat, J. (2015). Plant-level determinants of total factor productivity in Great Britain, 1997-2008. Journal of Productivity Analysis, 44(1), 1-20.

Idiong, I. C. (2007). Estimation of farm level technical efficiency in smallscale swamp rice production in cross river state of Nigeria: A stochastic frontier approach. World Journal of Agricultural Sciences, 3(5), 653-658.

Ismail, R., \& Tendot Abu Bakar, N. (2008). Technical efficiency of Malay firms in the manufacturing sector in Malaysia. International Journal of Management Studies (IJMS), 15(2), 143-163.

Ismail, A., Suh-Suh, Y., Ajis, M. N. E., \& Dollah, N. F. (2009). Relationship between occupational stress, emotional intelligence and job performance: An empirical study in Malaysia. Theoretical \& Applied Economics, 16(10).

Ismail, R., \& Abidin, S. Z. (2017). Determinant of technical efficiency of small and medium enterprises in Malaysian manufacturing firms. International Business Management, 11(2), 299-307.

Jarboui, S., Forget, P., \& Boujelben, Y. (2015). Efficiency evaluation in public road 
transport: A stochastic frontier analysis. Transport, 30(1), 1-14.

Khalifah, N. A. (2013). Ownership and technical efficiency in Malaysia's automotive industry: A stochastic frontier production function analysis. The Journal of International Trade \& Economic Development, 22(4), 509-535. https://doi. org/1 0.1080/09638199.2011.571702.

Mahadevan, R. (2001a). Assessing the output and productivity growth of Malaysia's manufacturing sector. Journal of Asian Economics, 12(4), 587-597.

Mahadevan, R. (2002b). A DEA approach to understanding the productivity growth of Malaysia's manufacturing industries. Asia Pacific Journal of Management, 19(4), 587600.

Mahadevan, R. (2002dc). Is there a real TFP growth measure for Malaysia's manufacturing industries? ASEAN Economic Bulletin, 178-190.

Mahadevan, R., \& Ibrahim, M. (2007). Competitiveness and workforce status in the Malaysian micro-electronics sector. Economics, East Asian Development Network (EADN), Malaysia.

Malaysia Productivity Corperation Report 2013 and 2014. Kuala Lumpur: Produktivitas Nasional Corporation, Petaling Jaya.

Malaysia Productivity Corperation Report 2014 and 2015. Kuala Lumpur: Produktivitas Nasional Corporation, Petaling Jaya.

Malaysia Productivity Corperation Report 2015 and 2016. Kuala Lumpur: Produktivitas Nasional Corporation, Petaling Jaya.

MITI. (2013). National Automotive Policy 2014. Ministry of International Trade and Industry.

MITI. (2014). National Automotive Policy 2014. Ministry of International Trade and Industry.

Mitra, A., Sharma, C., \& VeganzonesVaroudakis, M. A. (2013). Are reforms productive?: Explaining productivity and efficiency in the Indian manufacturing. Economic and Social Development: Book of Proceedings, 567.

Mohd Noor, Z., \& Ismail, R. (2007). Technical efficiency analysis in small and medium Scale industry in Malaysia. International Journal of Management Studies (IJMS), 14(1), 199-218.

Murthy, D. S., Sudha, M., Hegde, M. R., \& Dakshinamoorthy, V. (2009). Technical efficiency and its determinants in tomato production in Karnataka, India: Data envelopment analysis (DEA) approach. Agricultural Economics Research Review, 22(2), 215- 224.

Mustapha, N. H. N., Hashim, N. M. H., \& Yacob, R. (2013). Technical components of total factor productivity growth in Malaysian manufacturing industry. Applied Mathematics, 4(09), 1251.

National Accounts Gross Domestic Product (GDP) 2016. (2017). Putrajaya: Jabatan Perangkaan Malaysia.

Noor Aini, A. K., Basri, A. T., \& Putri Z. A. (2008). Are foreign multinationals more efficient? A stochastic production frontier analysis of Malaysia's automobile industry. International Journal of Management Studies, 15, 91-113.

Radam, A., Abu, M. L., \& Abdullah, A. M. (2008). Technical efficiency of small and medium enterprise in Malaysia: A stochastic frontier production model. International Journal of economics and Management, 2(2), 395-408.

Said, F., \& Said, S. M. (2004). Total factor productivity growth in the Malaysian manufacturing sector. International Journal of Economics, Management and Accounting, 12(2).

Sulaiman, N. (2012). An input-output analysis of the total factor productivity growth of the Malaysian manufacturing sector, 1983- 
2005. Jurnal Ekonomi Malaysia, 46(1), Wadud, M. (2008). Productivity growth 147-155.

Tingley, D., Pascoe, S., \& Coglan, L. (2005). Factors affecting technical efficiency in fisheries: stochastic production frontier and efficiency change in Malaysian manufacturing: Recent evidence from disaggregated data. Empirical Economics Letters, 7(5), 497-504.

approaches. Fisheries Research, 73(3), 363-376. 